\title{
An Improved MPPT Interleaved Boost Converter for Solar Electric Vehicle Application
}

\author{
F. Khoucha, A. Benrabah, O. Herizi, A. Kheloui \\ Département Electricité \& UER Electrotechnique \\ Ecole Militaire Polytechnique, Bordj El Bahri, Alger. \\ ALGERIE \\ fkhoucha04@yahoo.fr
}

\author{
M.E.H Benbouzid \\ University of Brest, EA 4325 LBMS \\ Rue de Kergoat, CS 93837, 29238 Brest Cedex 03, \\ FRANCE \\ m.benbouzid@ieee.org
}

\begin{abstract}
An interleaved boost dc/dc converter is developed featuring smaller input/output filters, faster dynamic response and lower device stress than conventional designs, for solar electric vehicle (SEV) applications. The converter is connected between the photovoltaic power generation and dc bus in a multisource energy storage system of a SEV. Typically, interleaved converters require a current control loop to reduce the input current ripples, the output voltage ripples, and the size of passive components with high efficiency. A Maximum Power Point Tracking (MPPT) controller for a Photovoltaic (PV) solar system associated to backup source (Battery) guarantees an uninterrupted power supply and assist the propulsion of the vehicle during transients and recover energy during regenerative braking. The design, construction, and testing of an experimental hardware prototype is presented, with the test results included.
\end{abstract}

Keywords-component: Interleaved dc-dc converter; Solar electric vehicle; MPPT; Energy storage system.

\section{INTRODUCTION}

Photovoltaic power generation technologies are expected to become an attractive power source for automotive applications because of their cleanness, high efficiency, and high reliability. Although PV systems exhibit good power capability during steady-state operation, the dynamic response of PV during transient and instantaneous peak power demands is relatively slow. Therefore, the PV system can be hybridized with energy storage systems (ESS) (e.g., batteries and/or supercapacitors) to improve the performance of the PV system during transient and instantaneous peak power demands of an electric vehicle (EV) and to recover energy through regenerative braking [1]-[2].

For these applications, a high-power $\mathrm{dc} / \mathrm{dc}$ converter is a key element that interfaces the PV or ESS with the dc bus in the powertrain of the SEV. Therefore, the dc system with multiple dc/dc converters may play an important role in the future powertrain system. The topology design of $\mathrm{dc} / \mathrm{dc}$ converters has been explained in many pieces of literature [3]. In addition, the design of high-power $\mathrm{dc} / \mathrm{dc}$ converters and their controller play an important role to control power regulation particularly for a common dc bus. The advantages and disadvantages of several topologies of $\mathrm{dc} / \mathrm{dc}$ converters, based on their component are presented and compared in [4].

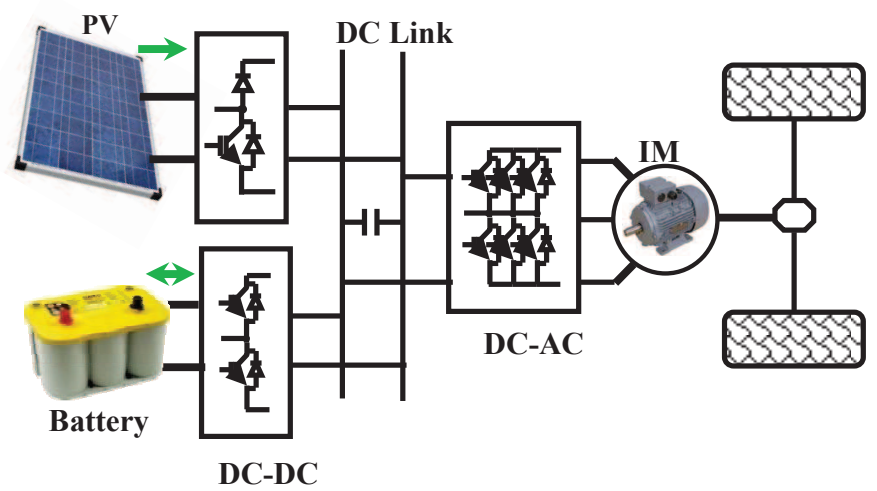

Figure 1. Block diagram multisource energy storage system of a SEV

Furthermore, for high-power applications, interleaved converters have been proposed for use in electric vehicle applications [5].

The solar electric vehicle (SEV), as shown in Fig. 1, utilizes a PV panel as the main power source and the ESS (e.g., batteries) as the auxiliary power source to assist the propulsion of the vehicle during transients and to recuperate energy during regenerative braking. In this configuration, the PV is connected to the dc bus through an interleaved boost converter, whereas the ESS is connected to the dc bus via a bidirectional $\mathrm{dc} / \mathrm{dc}$ converter.

The $\mathrm{dc} / \mathrm{dc}$ converter is one of the most important components in a PV powered system. It allows a desired level of dc voltage to be obtained without having to increase the primary source size. As a result, this paper will focus on a $\mathrm{dc} / \mathrm{dc}$ converter that interfaces the PV with the powertrain of SEVs. In high-power boost converters, the major design aspect is the selection of the boost inductor and the output capacitor. The major concern is the size, cost, and weight of such a high-power inductor that is the single heaviest component in the entire $\mathrm{dc} / \mathrm{dc}$ converter. To reduce the inductor size and weight, a small inductance value is required. 
In addition, the $\mathrm{dc} / \mathrm{dc}$ converter performance directly influences the characteristics of the PV or the ESS.

Indeed, the ripple and harmonic content of the current is one of the various phenomena influencing PV efficiency as well as battery lifetime [6]. So the main objective of this research is to minimize inductor size, capacitor, current/voltage ripples, and harmonic content.

In this paper, a special structure called interleaved boost converter has been studied and analyzed to reduce the size and weight of the passive components, such as the inductor, capacitor, and input/output electromagnetic interference (EMI) filter. Dual-loop control strategy based on TMS320F2812 DSP environment has been developed to implement the whole control strategy multisource energy storage system with vehicle dynamic. Simulation and experimental results are provided.

\section{PV SYSTEM MODEL}

\section{A. PV Model}

The mathematical model associated with a cell is deduced from that of a diode PN junction. It consists on the addition the photovoltaic current $I_{p h}$ (which is proportional to the illumination), and a term modeling the internal phenomena [7]. The electrical equivalent circuit is shown in Fig.2.The cell output current $I$, is then written:

$$
I=I_{p h}-I_{0}\left(e^{q\left(V+R_{S} I / n k T\right)}-1\right)
$$

Where D represents the behavior of the cell in darkness, the internal losses are modeled by serial resistances Rs.

$n$ : Diode ideality factor.

$I_{0}$ : Diode reverses saturation current (A).

$V$ : Output voltage of PV cell (V).

$T$ : Cell Temperature in Kelvin.

$q$ : The elementary charge constant.

$k$ : The Boltzmann constant.

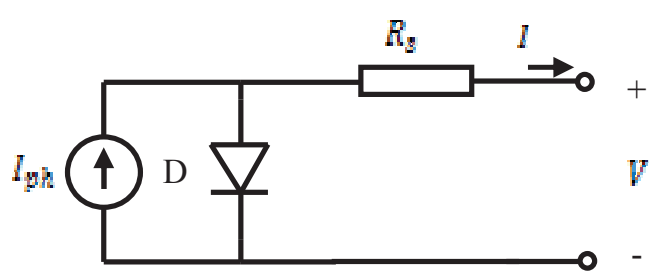

Figure 2. PV cell equivalent circuit

The SCA module BP Solar SX 50 [8] is selected like model of simulation under MATLAB/Simulink. "It belongs to the series of module SXTM of BP Solar. 1 Tab. 1 summarizes its standard electric characteristics: $\uparrow$
ELECTRIC CHARACTERISTICS OF SOLAR ARRAY BP SOLAR BP SX 50.

\begin{tabular}{|l|l|}
\hline Maximum power $\left(P_{\max }\right)$ & $50 \mathrm{~W}$ \\
\hline Operating Voltage $\left(V_{m p p}\right)$ & $16.8 \mathrm{~V}$ \\
\hline Operating Current $\left(I_{m p p}\right)$ & $2.97 \mathrm{~A}$ \\
\hline Short-circuit Current $\left(I_{s c}\right)$ & $3.23 \mathrm{~A}$ \\
\hline Open circuit voltage $\left(V_{O C}\right)$ & $21 \mathrm{~V}$ \\
\hline Temperature coefficient of $I_{S C}$ & $(0.065 \pm 0.015) \% /{ }^{\circ} \mathrm{C}$ \\
\hline Temperature coefficient of $V_{O C}$ & $-(80 \pm 10) \mathrm{mV} /{ }^{\circ} \mathrm{C}$ \\
\hline Temperature coefficient of the power & $-(0.5 \pm 0.05) \% /{ }^{\circ} \mathrm{C}$ \\
\hline
\end{tabular}

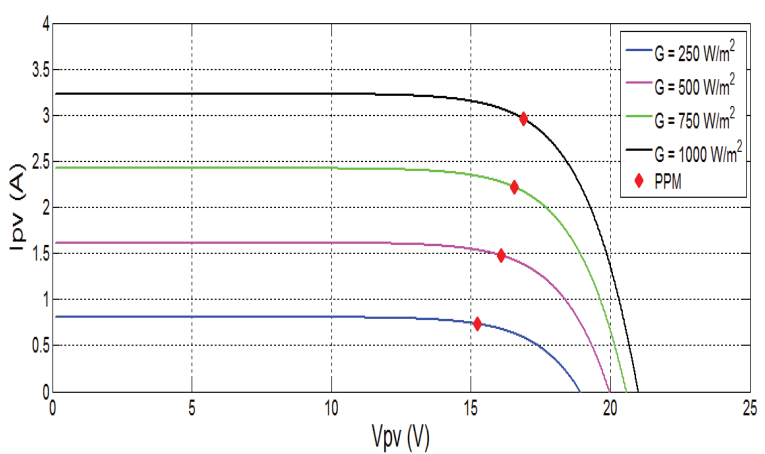

Figure 3. I-V family curves with proposed model for different irradiation levels

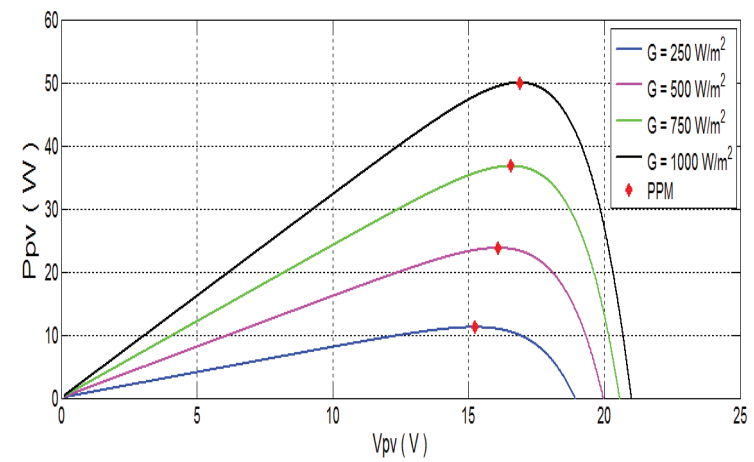

Figure 4. P-V family curves with proposed model for different irradiation levels

For lighting conditions and temperature data, the characteristics of current-voltage and power-voltage $P=\mathrm{f}(V)$ show an operating point at maximum power.

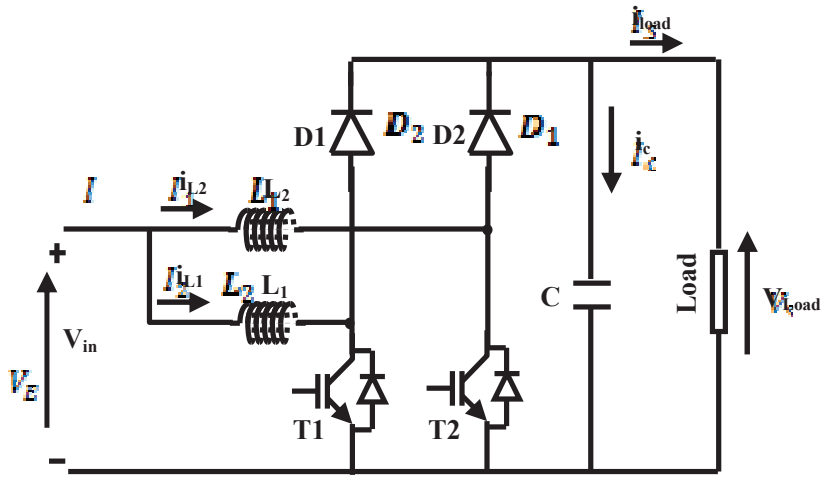

Figure 5. Two cell interleaved boost converter 
The photocurrent is nearly proportional to the light or luminous flux $(G)$. The following figures (Fig. 3 and Fig. 4) show the influence of illumination on the current and power. The photocurrent created in a photocell is proportional to the surface $\mathrm{S}$ of the junction subjected to sunlight

\section{B. Interleaved boost converter model}

Solar cells have relatively low conversion efficiency and the improvement of overall system efficiency is an important design factor: in the area of PV systems. This can be partly achieved by using high-efficiency intermediate converters with maximum power point controllers (MPPT). The main requirements of these converters are: (1) the converter input current has small ripple and (2) the converter efficiency should be high, even at lower intensity insolations. The intermediate converter produces a chopped output dc voltage and controls the average dc voltage applied to the load.

Further, the converter continuously matches the output characteristic of the PV generator to the input characteristic of the load, so that maximum power is extracted from the solar cell arrays (SCA). Many different types of intermediate converters with maximum power point tracking controllers for PV systems have been proposed [9]. Simple converters such as buck and boost converters enter into discontinuous current mode at lower intensity insolations, resulting in improper utilization of power devices and increased conduction losses due to increased current ripple. To reduce the input current ripple and Lo alleviate the problem of discontinuous input current, we propose to use two cell interleaved boost converter for PV applications. Although this converter increases the number of components compared to conventional boost converter, the actual increase in cost may not be significant. Further, interleaved operation has many desirable features such as a lower value of ripple amplitude, high ripple frequency in the resulting input and output waveforms, it reduces maintenance and increases reliability and fault tolerance.

The P\&O-MPPT is applied to PV systems to extract maximum available power from the SCAs at all insolations. Different methods of peak power tracking schemes have been proposed by using different control strategies [9]. The Perturbation and Observation (P\&O) method is a widely used approach to MPPT. As the name of the P\&O method states, this process works by perturbing the system by increasing or decreasing the array operating voltage and observing its impact on the array output power (Fig. 6). It employs a microprocessor with the values for panel voltage $V$ and output panel current $I$ as its input values and the desired operating voltage $V_{r e f}$ as its output value.

\section{Converter linked to the battery}

The battery charger/discharger system is composed by a bidirectional (BD) converter as shown in Figure 7. This converter operates in two modes: (i) buck mode, charging the batteries; and (ii) boost mode, discharging the batteries. This converter is also responsible for the dc bus voltage regulation according to the power produced and demands [8].

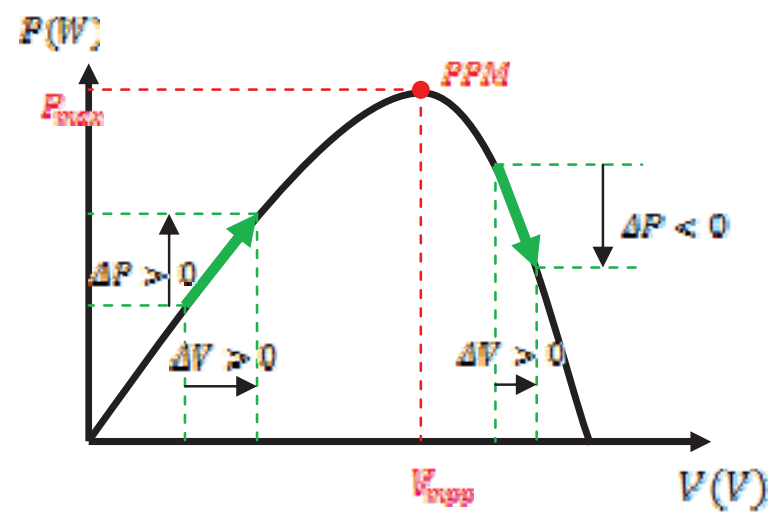

Figure 6. Power tracking process

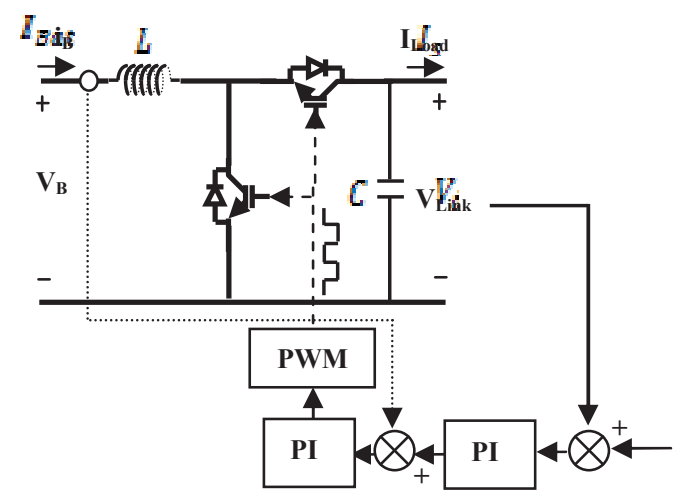

Figure 7. Bidirectional battery charger/discharger converter.

\section{SIMULATION ףRESULTS}

In order to simulate the system and to test the validity of the approach proposed, the MATLAB-Simulink software was selected. The load is modeled by a variable resistance, the temperature is supposed to be constant $\left(\mathrm{T}=25^{\circ} \mathrm{C}\right)$ and the illumination received by the panel has the profile presented on the Figure 8 . These fast variations of illumination do not represent the real case (the illumination varies generally much less brutally), but that allow to observe the evolution of algorithm MPPT in the most critical case.

Under given conditions, we can see that the SCA power follows the point of maximum power (Fig. 9). The maximum power point control algorithm changes the duty ratio of the converter appropriately, so as to reach the MPP. Further, the algorithm tracks the MPP continuously by adjusting the converter duty ratio such that the load power is maximum. With this algorithm the operating voltage $\mathrm{V}$ is perturbed with every MPPT cycle. As soon as the MPP is reached, the operating voltage will oscillate around $V_{m p p}$. This causes a power loss which depends on the perturbation step width. 


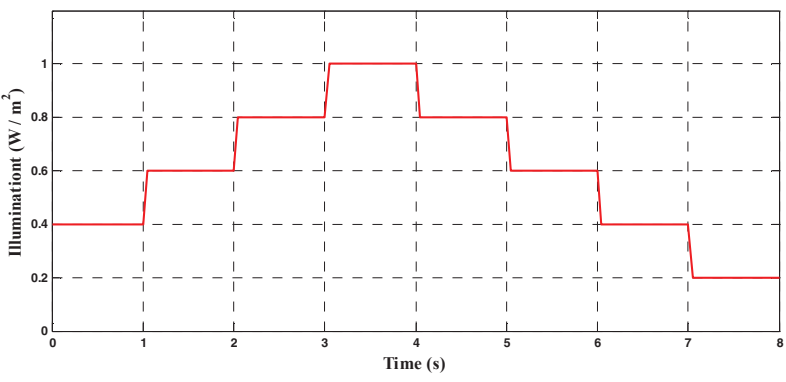

Figure 8. Illumination Profile

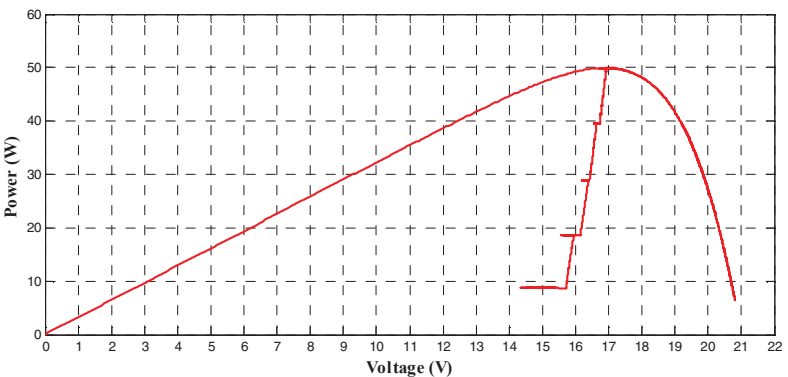

Figure 9. MPPT response on the interval $[3,8] \mathrm{s}$

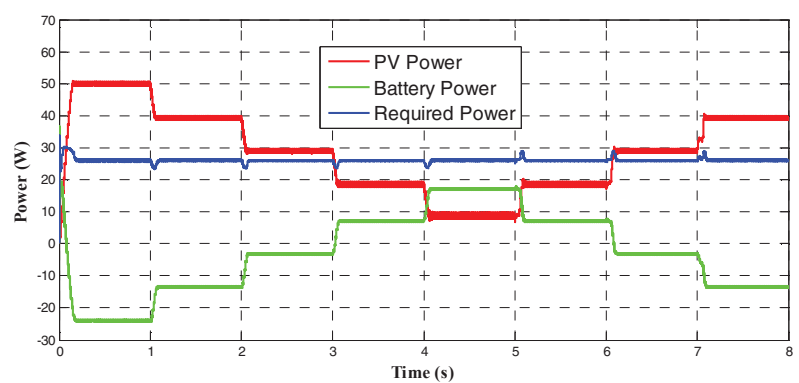

Figure 10. Powers evolution for a variable illumination

According to the scenario selected, we can also observe the powers delivered by the different elements linked to dc bus (Fig. 10).

Two scenarios appear:

- Supply the load and charge the battery by the PV panels if the power of the SCA exceeds the power required by the load.

- Supply the load by PV panels and the battery if the power of the panel is insufficient.

The dc bus voltage is maintained constant by the control system regulation (Fig.11).

This same reasoning can be applied for a variable load, and a constant illumination. The sum of the powers provided by the battery and the panel always equalizes with the power required by the load as shown on Fig. 10. The dc bus voltage is always maintained constant (Fig.11).

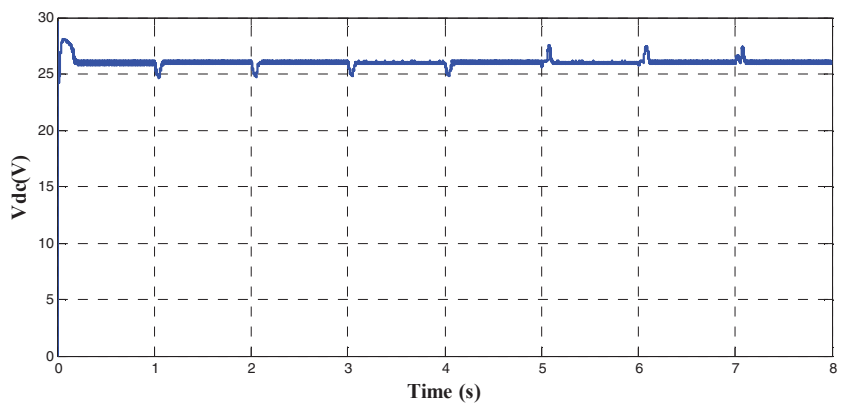

Figure 11. De bus regulation

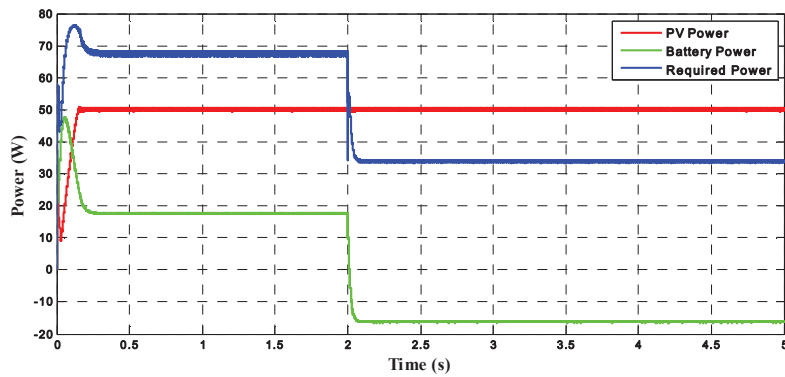

Figure 12. Power characteristics of a PV array under variable load

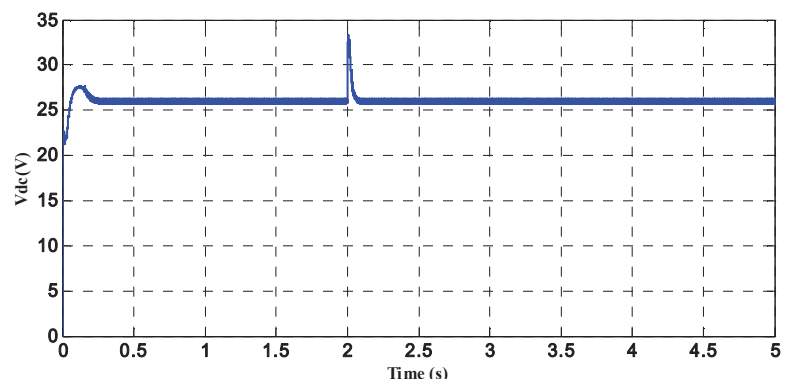

Figure 13. dc bus regulation

\section{EXPERIMENTAL RESULTS}

There are some drawbacks of field testing with real photovoltaic modules, such as costly, heavy dependence on weather condition and time consuming. PV emulator can emulate the current-voltage output characteristics of PV arrays under different temperature and solar irradiation; therefore it is a good substitute to help test maximum power point trackers of PV system in laboratory regardless of actual weather or temperature conditions.

There are several methods to implement PV emulator by analog or digital technology, including: (i) amplifying the output of current and voltage of a PV cell or a photo diode; (ii) constructing a PV cell equivalent circuit with constant current source and diode-resistor network; (iii) using a switchedmodule power converter controlled by digital chips or analog circuit to fill the current-voltage output characteristics of PV arrays. The third method has been reported mostly in recent 
years because of digital technology development and its advantage in rapid system prototyping [9].

As shown on Figure 14, a DSP-controlled PV emulator consists of a step-down dc-dc power converter. It simulates the current-voltage characteristics of the PV arrays under different temperature and solar irradiation. The mathematic modeling of the I-V curve of PV arrays is investigated and a control strategy is put forward for the PV emulator. A $50 \mathrm{~W}$ prototype (BP Solar SX50) has been built and tested. The experiment results (Fig. 15) show that the PV emulator could shift smoothly on its characteristic I-V curve, which is suitable for further experiments of maximum power point tracking in the PV system.

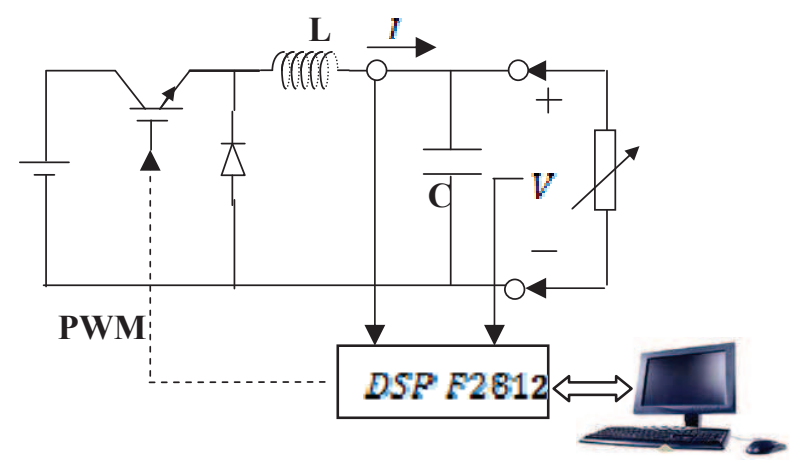

Figure 14. Hardware prototype of PV emulator.

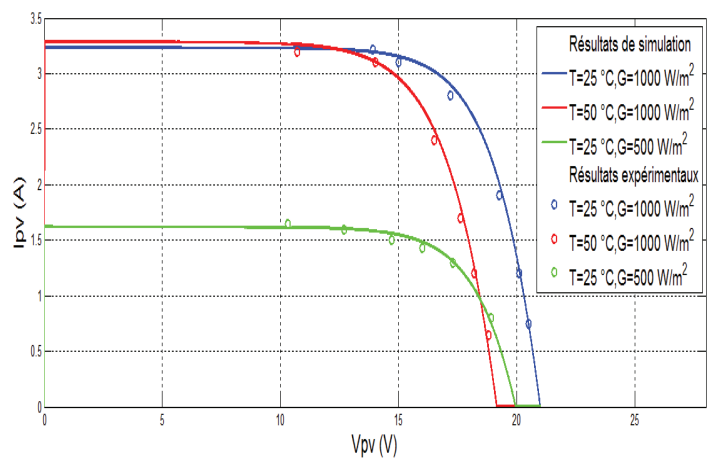

Figure 15. Operation Points of PV emulator.

The proto-type hardware built consists of:

- A photovoltaic emulator modeling the panel BP solar SX 50.

- An interleaved boost converter connected to PV emulator $\left(f=10 \mathrm{kHz}, L_{l}=L_{2}=1.5 \mathrm{mH}, \mathrm{C}=288 \mu \mathrm{F}\right)$.

- A Lead-Acid battery of $12 \mathrm{~V}$ with a capacity of $12 \mathrm{Àh}$.

- $\quad$ Bidirectional battery charger/discharger converter $(f=$ $10 \mathrm{kHz}, L=2.6 \mathrm{mH}$ ).

- A variable resistor simulating the load.

- The control board mainly consists of a TMS320LF2812 DSP.
The digitally controlled MPPT technique (P\&O) was first tested with changing illumination levels .As can be seen on Fig. 16 and Fig. 17, the algorithm tracks the MPP continuously. With resistive load variation (Fig. 18 and 19), the operating point returns always to the maximum power point.

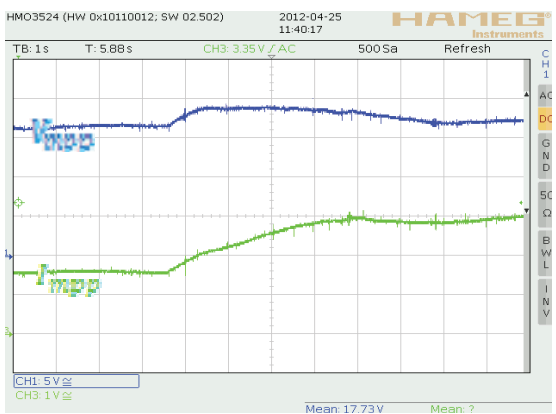

Figure 16. Variation of the illumination from $500 \mathrm{~W} / \mathrm{m} 2$ to $1000 \mathrm{~W} / \mathrm{m}^{2}$

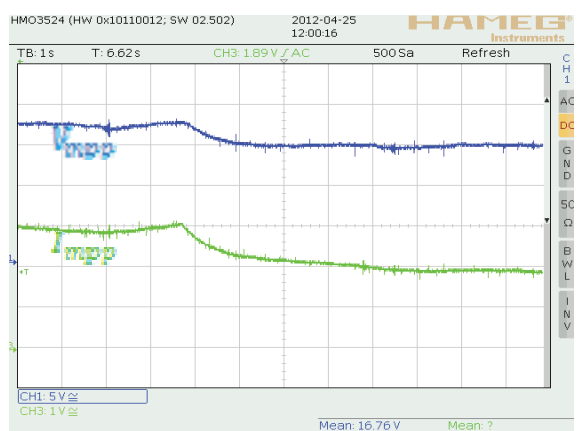

Figure 17. Variation of the illumination from $1000 \mathrm{~W} / \mathrm{m}^{2}$ to $700 \mathrm{~W} / \mathrm{m}^{2}$

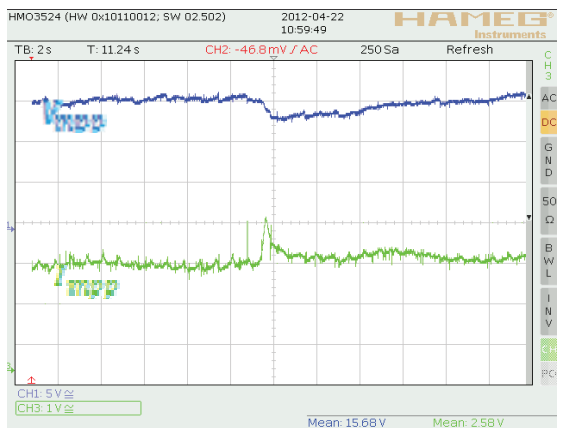

Figure 18. Decreasing the resistive load

The Figure 20, 21, and 22 illustrates the dc bus voltage and the battery current when changing illumination or for various value of resistive load. 


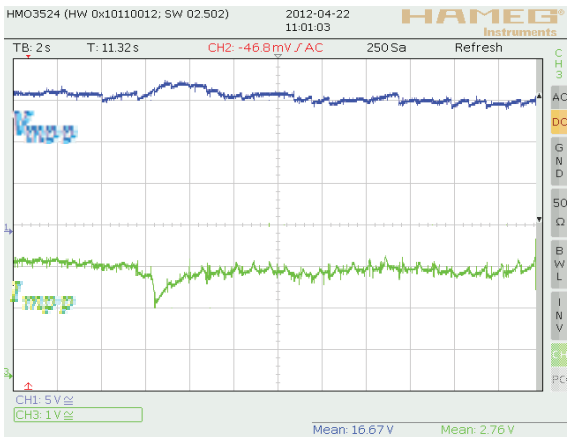

Figure 19. increasing the resistive load

When the illumination is reduced from $1000 \mathrm{~W} / \mathrm{m}^{2}$ to 500 $\mathrm{W} / \mathrm{m}^{2}$, the power produced decreases. Consequently, the $\mathrm{dc}$ bus level decreases due to the require power, illustrated in the Figure 20. This way, the control of the bi-directional converter interrupts the charge process of the batteries, and begins the discharge procedure (positive current on the batteries) in order to regulate the dc bus voltage. When the illumination varied from 500 to $1000 \mathrm{~W} / \mathrm{m}^{2}$, the dc bus level increases as can be observed in Figure 21, the control of the bi-directional converter interrupts the discharge process of the batteries, and begins the charge procedure (negative current on the batteries) in order to regulate the dc bus voltage. For a constant illumination, the load resistance has been manually changed (see Fig. 22) and we can see that the controlled dc bus voltage remains at the desired value. If the current delivered by the SCA is insufficient, the battery provides the required power.

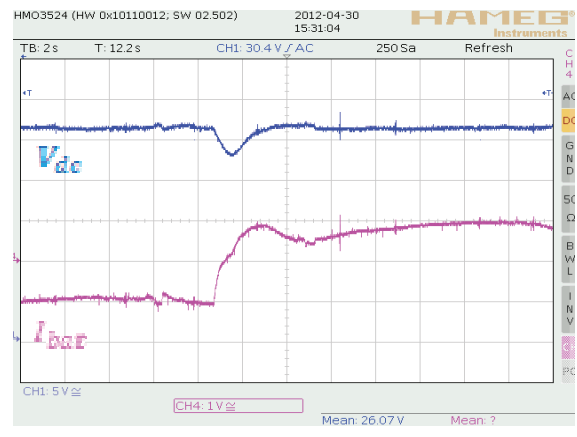

Figure 20. Variation of the illumination from $1000 \mathrm{~W} / \mathrm{m}^{2}$ to $500 \mathrm{~W} / \mathrm{m}^{2}$

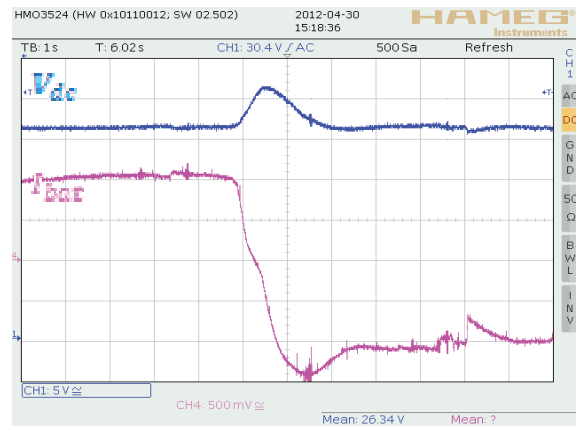

Figure 21. Variation of the illumination from $500 \mathrm{~W} / \mathrm{m}^{2}$ to $1000 \mathrm{~W} / \mathrm{m}^{2}$

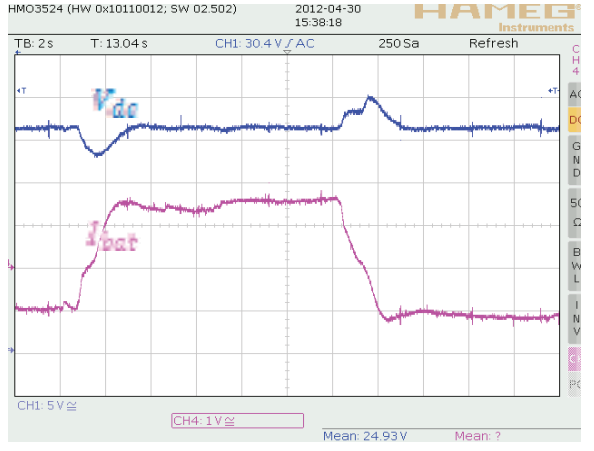

Figure 22. Load variation

\section{CONCLUSIONS}

In this paper, a new power supply system was developed to utilize solar photovoltaic (PV) power and mains from a utility power supply to feed the dc outputs and charge the back-up battery. Charging of the battery is carried out during the daylight when there is appreciable radiation intensity or whenever there is a supply from the utility power source.

Simulation of the whole system is also given. This result gives good functioning and a correctly attempt objectives. An energy assessment is also presented for different flows of energies. To validate the present work, experimentations have been carried out by authors and exhibit good performances even in the presence of load parameter variation and changing illumination for the photovoltaic panel.

\section{REFERENCES}

[1] K. Jin, X. Ruan, M. Yang, and M. Xu, "A hybrid fuel cell power system,” IEEE Trans. Ind. Electron., vol. 56, no. 4, pp. 1212-1222, Apr. 2009.G.

[2] A. Emadi, Y. J. Lee, and K. Rajashekara, "Power electronics and motor drives in electric, hybrid electric, and plug-in hybrid electric vehicles,"IEEE Trans. Ind. Electron., vol. 55, no. 6, pp. 2237-2245, Jun. 2008

[3] X. Kong and A. M. Khambadkone, "Analysis and implementation of a high efficiency, interleaved current-fed full bridge converter for fuel cell system," IEEE Trans. Power Electron., vol. 22, no. 2, pp. 543-550, Mar. 2007.

[4] W. Li and X. He, "Review of nonisolated high-step-up DC/DC converters in photovoltaic grid-connected applications," IEEE Trans. Ind. Electron., vol. 58, no. 4, pp. 1239-1250, Apr. 2011.

[5] Yuan. Li, Taewon Lee, Fang. Z. Peng, and Dichen Liu. "A Hybrid Control Strategy for Photovoltaic Simulator ". IEEE Copyright(c),2009.

[6] M. I. Desconzi, R. C. Beltrame, C. Rech, L. Schuch, and H. L. Hey"Photovoltaic Stand-Alone Power Generation System with Multilevel Inverter". International Conference on Renewable Energies and Power Quality (ICREPQ'11). Las Palmas de Gran Canaria (Spain), 13th to 15th April, 2010.

[7] Ryan Campbell, "A circuit-based photovoltaic array model for power system studies", Proceedings of the 39th North American Power Symposium (NAPS 2007), Las Cruces, NM, USA, October 2007.

[8] BP Solar "BP SX 50 - 50W Multi-crystalline Photovoltaic Module Datasheet", 2001 